\title{
Modernization of high pressure fuel pump for operation on mixed rapeseed-mineral fuel
}

\author{
Aleksandr S. Averyanov ${ }^{1, *}$, Stanislav N. Vlasov ${ }^{1}$, Evgeniy G. Rotanov ${ }^{2}$, and Anton A. \\ Khokhlov ${ }^{3}$ \\ ${ }^{1}$ Dimitrovgrad Engineering and Technology Institute - a branch of the National Research Nuclear \\ University MEPhI, Ulyanovsk Region, Dimitrovgrad, Russian Federation \\ ${ }^{2}$ Volga Cossack Institute of Management and Food Technologies (branch), FSFEI of HE Moscow \\ State University of Technology and Management named after K.G. Razumovskiy (First Cossack \\ University), Russia \\ ${ }^{3}$ Technological Institute - Branch of Ulyanovsk State Agrarian University named after P.A. Stolypin, \\ Russia
}

\begin{abstract}
The results of experimental studies, the purpose of which is to assess the effect of heating of diesel mixed fuel on the cycle supply and fuel pressure in the supra-plunger space of the high-pressure fuel pump (HPFP) are presented. A correction device for cyclic fuel supply is presented (RF patent No. 122708). The principle of its action is described. The results of experimental studies of HPFPs with the proposed device for adjusting the cyclic fuel supply are presented.
\end{abstract}

\section{Introduction}

Fuel combustion in the diesel engine cylinders takes place over a very short period, and the completeness of its combustion depends on the degree of air use in the combustion chamber. The latter is provided by the fuel jet's penetration depth and the degree of fuel atomization throughout the volume. These parameters directly depend on the fuel pressure in the supra-plunger space of the high-pressure fuel pump (HPFP) and on the cyclic fuel supply [1]. Experiments show that, depending on the viscosity, the fuel pressure above the plunger and the cyclic injection of the HPFP vary significantly. Obviously, too viscous fuel will enter the combustion chamber in insufficient quantities. On the other hand, too low a viscosity of the fuel can lead to insufficient tightness of the plunger pair [2].

The viscosity of diesel fuel cannot be reduced below the permissible limits also because in diesel engines the fuel simultaneously plays the role of lubricating of mating (plunger bush bearing, sprayer needle - body, pressure valve - seat). Mating and precision pairs of HPFP wear out faster on fuel with low lubricity [3, 4, 5].

Currently, diesel mixed fuel (DMF) [6], which is a mixture of mineral fuel and vegetable oil, is widely used in diesel engines of automotive vehicles. When DMF's viscosity increases, the load on the injection pump's elements also increases. Since the viscosity of DMF directly depends on the concentration of vegetable oil (VO) in it, we carried out experimental and theoretical studies aimed at studying the influence of the

*Corresponding author: averyanovs.as@mail.ru 
percentage composition of DMF on the cyclic supply and pressure of fuel in the supraplunger space of the injection pump. A refined mathematical model of the fuel supply process is described, considering the concentration of rapeseed oil in mixed rapeseedmineral fuel and the physical properties of the latter, a theoretical justification of the method for determining the average effective cross section of nozzles and injection fuel pipelines is performed.

\section{Experimental research methodology}

To assess the influence of the percentage composition of mixed rapeseed-mineral fuel (MRMF) on the cyclic supply of HPFPs, we conducted experimental and theoretical studies. The experimental comparative studies of HPFP were carried out on a non-powered unit with the speed controller turned off at various speed modes, beginning from the starting ones $(200 \mathrm{rpm})$ and ending with nominal revolutions $(1100 \mathrm{rpm})$ at $100 \mathrm{rpm}$ intervals. The HPFP operation was carried out on mineral diesel fuel of grade L-0.2-40, rapeseed oil (100\% VO) and DMF of the following composition: $10 \% \mathrm{VO}+90 \% \mathrm{DF} ; 25 \%$ VO + 75\% DF; 37\% VO + 63\% DF; $50 \%$ VO + 50\% DF; $63 \%$ VO + 37\% DF; $75 \%$ VO+ $25 \%$ DF; $90 \% \mathrm{VO}+10 \% \mathrm{DF}$. Before starting the research, HPFP was adjusted to the nominal cyclic fuel supply (72 $\pm 1.5 \mathrm{~mm} 3 /$ cycle), corresponding to the supply of the D-243 diesel on mineral diesel fuel [6]. The studies were carried out at a constant fuel temperature of $30^{\circ} \mathrm{C}$, as well as under heating of MRMF in the temperature range from $30^{\circ} \mathrm{C}$ to $80^{\circ} \mathrm{C}$. The fuel was heated in such a way that the viscosity of the heated MRMF corresponded to the viscosity of mineral DF at a temperature of $30^{\circ} \mathrm{C}$.

The cyclic fuel supply calculation was carried out using the fourth-generation 'INJECTION' software package developed at MSTU named after N.E. Bauman. [7, 8]

\section{The results of experimental studies}

The graphs show the theoretical and experimental data of the dependence of the pressure in the supra-plunger space (P s.p.s.) on the speed of the camshaft of HPFP (n c.s.) and on the percentage composition of the MRMF, respectively, under normal conditions and when heated.

From the graph in Figure 1 it is seen that with an increase in the concentration of rapeseed oil in the MRMF and the revolutions of the camshaft of the HPFP (n c.s.) under normal conditions, there is a significant increase in pressure in the supra-plunger space $(\mathrm{P}$ s.p.s.). This is confirmed by both experimental (shown by the solid line) and theoretical (shown by the dashed line) studies. Such an increase in pressure leads to an increase in the load on the fuel equipment and malfunctions in its operation. [9]

From the graph in Figure 2 it can be seen that when heating diesel mixed fuels to temperatures at which their viscosity corresponds to the viscosity of diesel fuel under normal conditions and an increase in the revolutions of the camshaft of HPFP (n c.s.), there is no significant increase in pressure in the supra-plunger space (P s.p.s.). This trend is observed up to the use of MRMF with a content of $75 \%$ VO heated to $80^{\circ} \mathrm{C}$. A further increase in the concentration in MRMF to $90 \% \mathrm{VO}$ and $100 \% \mathrm{VO}$ and their heating to 80 ${ }^{\circ} \mathrm{C}$ do not lead to a decrease in pressure in the supra-plunger space in comparison with the parameters under normal conditions. This is also confirmed by both experimental (shown by the solid line) and theoretical (shown by the dashed line) studies. 


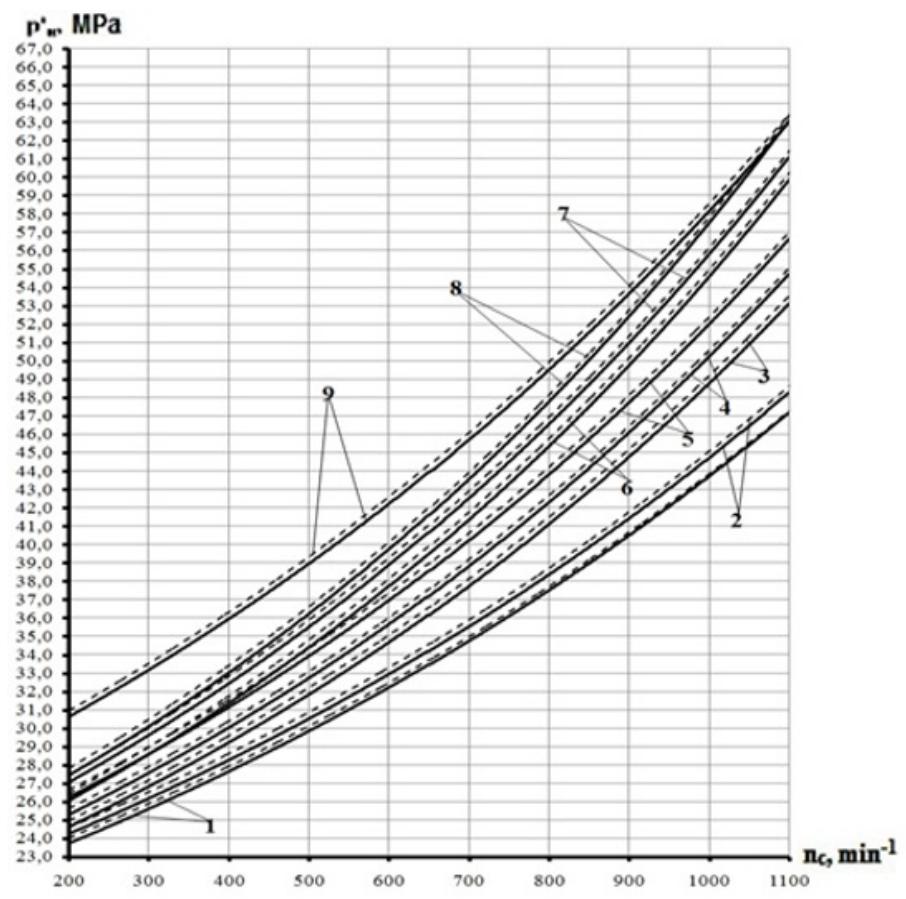

Fig. 1. Dependencies of pressure in the supra-plunger space $\left(\mathrm{P}_{\text {н }}\right)$ on the camshaft revolutions of HPFP ( $\mathrm{n}_{\mathrm{c} .}$ ) and the percentage of MRMF under normal conditions: 1 - 100\% DF, 2 - 10\% RO, 3 25\% RO, 4 - 37\% RO, 5 - 50\% RO, 6 - 63\% RO, 7 - 75\% RO, 8 - 90\% RO, 9 - 100\% RO

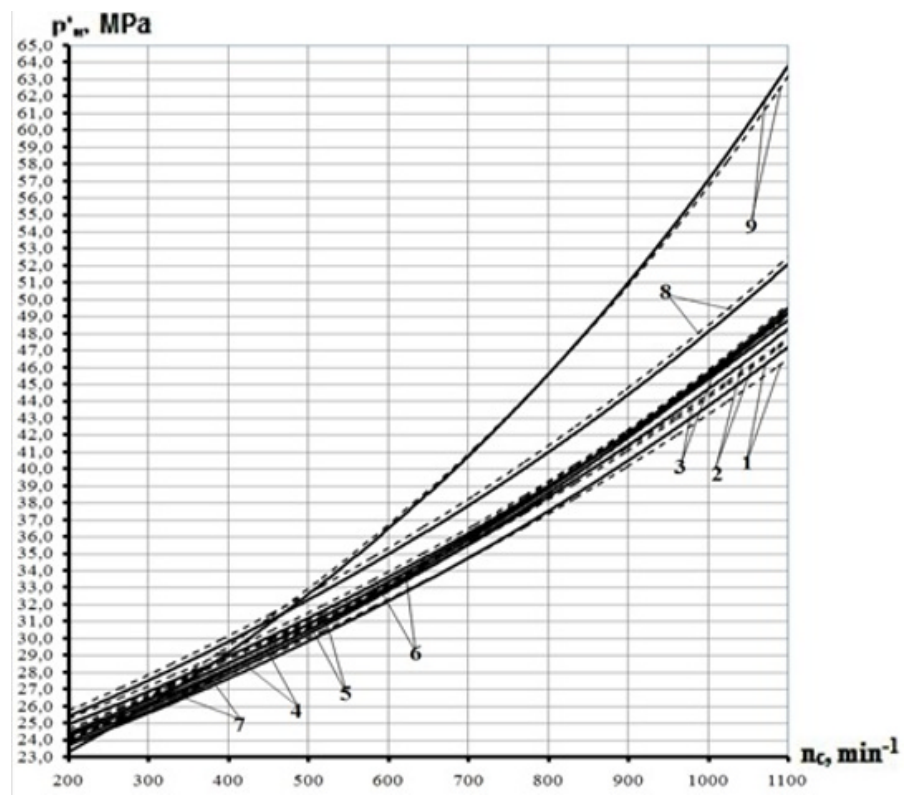

Fig. 2. Dependences of the pressure in the supra-plunger space $\left(\mathrm{P}_{\mathrm{H}}{ }_{\mathrm{H}}\right)$ on the revolutions of the camshaft of HPFP $\left(\mathrm{n}_{\mathrm{c}}\right.$.) and the percentage composition of MRMF when heated: $1-100 \% \mathrm{DF} 30^{\circ} \mathrm{C}, 2$ $-10 \%$ RO $30^{\circ} \mathrm{C}, 3-25 \%$ RO $50^{\circ} \mathrm{C}, 4-37 \%$ RO $60^{\circ} \mathrm{C}$, $75 \% \mathrm{RO} 80^{\circ} \mathrm{C}, 8-90 \% \mathrm{RO} 80^{\circ} \mathrm{C}, 9-100 \% \mathrm{RO} 80^{\circ} \mathrm{C}$ $5-50 \% \mathrm{RO} 70^{\circ} \mathrm{C}, 6-63 \% \mathrm{RO} 80^{\circ} \mathrm{C}, 7-$ 
Also, as a result of the studies, the high-speed characteristics of HPFP were obtained at various concentrations of rapeseed oil in MRMF, which after processing are presented in graphs (Fig. 3 and 4).

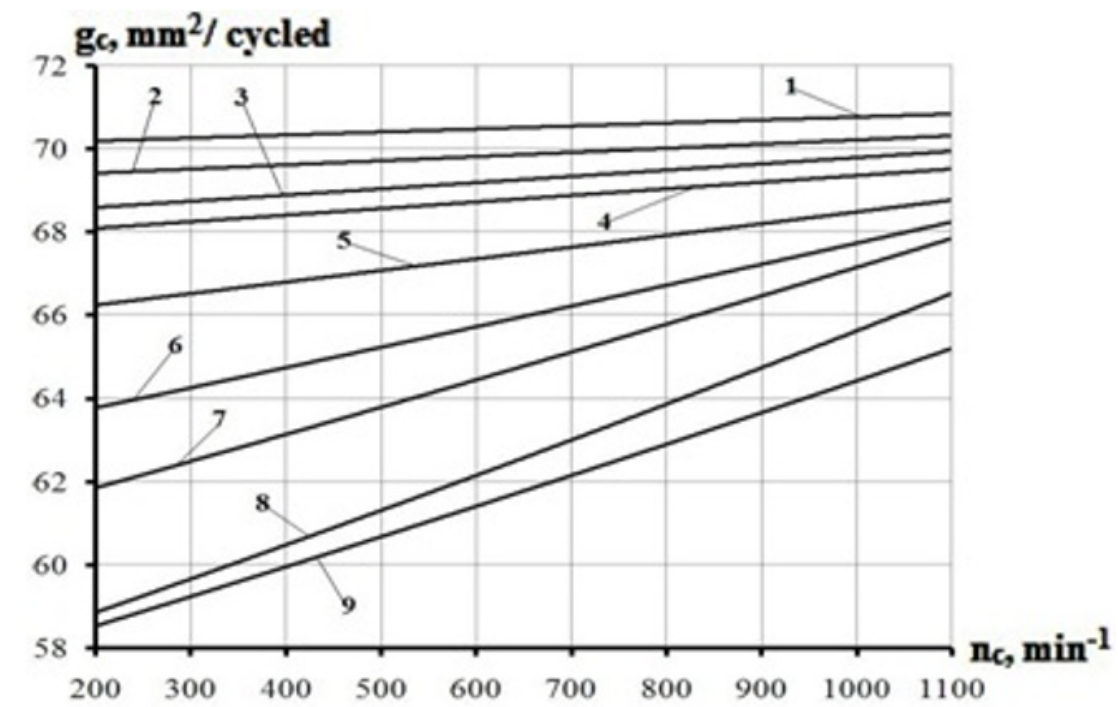

Fig. 3. High-speed characteristic of HPFP at various concentrations of rapeseed oil in MRMF (temperature $30{ }^{\circ} \mathrm{C}$ ): $1-100 \% \mathrm{DF}, 2-10 \% \mathrm{RO}, 3-25 \% \mathrm{RO}, 4-37 \% \mathrm{RO}, 5-50 \% \mathrm{RO}, \quad 6-$ 63\%RO, 7 - 75\%RO, 8 - 90\%RO, 9 - 100\%RO

The analysis of Figure 3 shows that with an increase in the concentration of rapeseed oil in MRMF and the rotational speed of the camshaft of HPFP at a temperature of $30^{\circ} \mathrm{C}$, a sharp decrease in the cyclic supply of fuel occurs. Such a decrease in the cyclic supply negatively affects the start of the engine and its operation as a whole, since at the same time the power decreases and the speed indicators deteriorate.

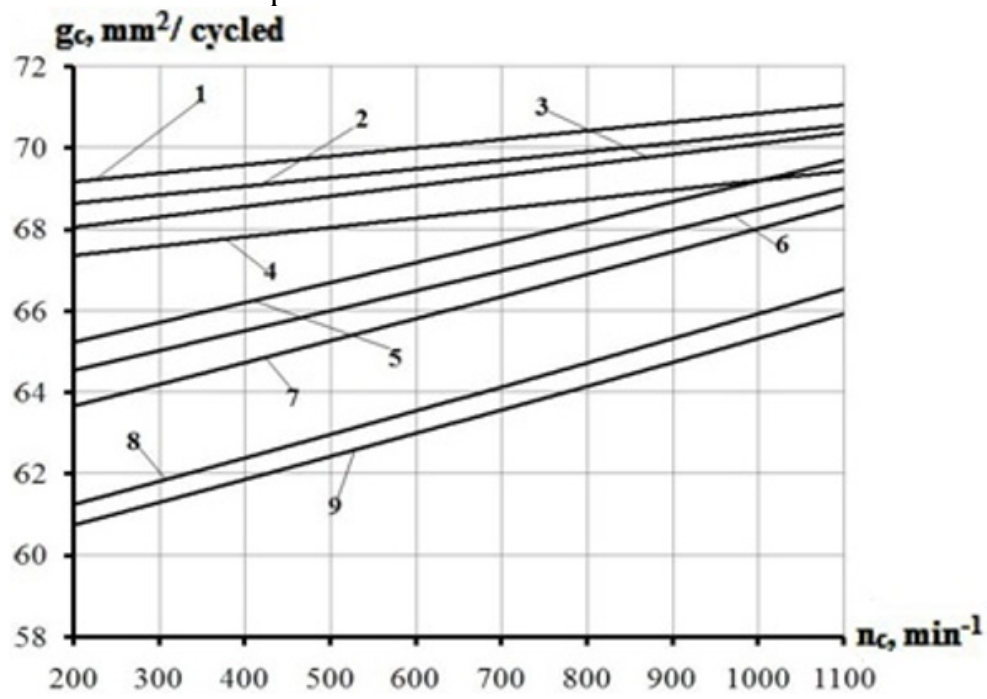

Fig. 4. High-speed characteristic of HPFP for various concentrations of rapeseed oil in MRMF (when heating fuel from $30{ }^{\circ} \mathrm{C}$ to $80{ }^{\circ} \mathrm{C}$ ): $1-100 \% \mathrm{DF} 30^{\circ} \mathrm{C}, 2-10 \%$ RO $30^{\circ} \mathrm{C}, 3-25 \%$ RO $50^{\circ} \mathrm{C}, 4-$ $37 \%$ RO $60^{\circ} \mathrm{C}, 5-50 \%$ RO $70^{\circ} \mathrm{C}, \quad 6-63 \%$ RO $80^{\circ} \mathrm{C}, 7-75 \%$ RO $80^{\circ} \mathrm{C}, 8-90 \% \mathrm{RO} 80^{\circ} \mathrm{C}, 9-$ $100 \% \mathrm{RO} 80^{\circ} \mathrm{C}$ 
The analysis of Figure 4 shows that when heating diesel mixed fuels to temperatures at which their viscosity corresponds to the viscosity of diesel fuel at a temperature of $30^{\circ} \mathrm{C}$, with an increase in the concentration of rapeseed oil in MRMF and the speed of the camshaft of HPFP, the cyclic fuel supply also decreases, but not as sharp as at a temperature of $30{ }^{\circ} \mathrm{C}$. Such a tendency is observed in the entire range of camshaft rotational speed frequencies, up to the use of MRMF with a content of $50 \%$ VO heated to a temperature of $70^{\circ} \mathrm{C}$. A further increase in the concentration of VO in MRMF and their heating to a temperature of $80^{\circ} \mathrm{C}$ do not lead to a significant increase in the cyclic fuel supply as compared to the fuel supply at a temperature of $30^{\circ} \mathrm{C}$.

\section{Fuel Cycle Correction Device}

To solve the problem of reducing the cyclic feed when working on mixed fuels on HPFP, the proposed device for correcting the cyclic fuel supply was installed (RF patent No. 122708) (Fig. 5).

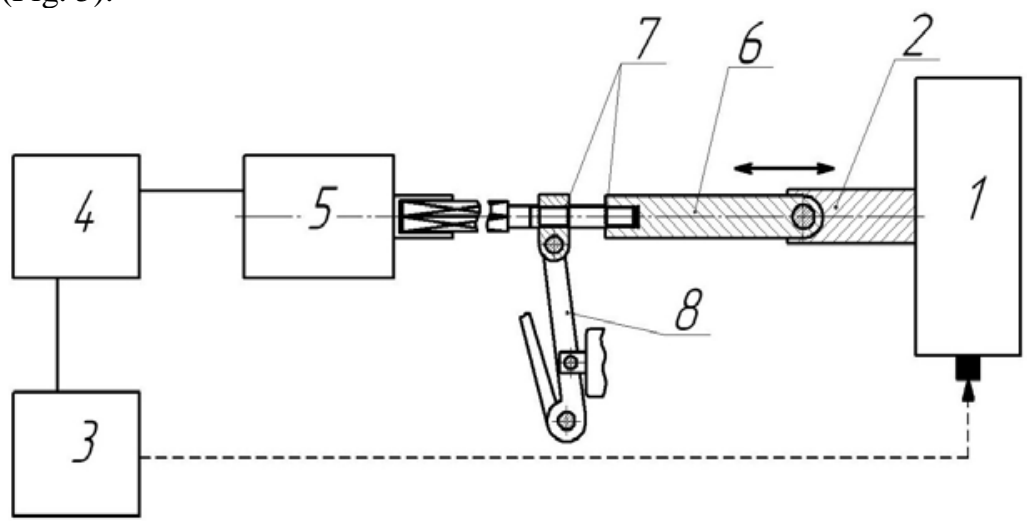

Fig. 5. The device for adjusting the cyclic fuel supply according to the viscosity-temperature characteristic

According to the known viscosity-temperature characteristic of mixed fuel, previously embedded in the form of a machine program in electronic unit 4, the latter having received and processed an informative signal from the temperature sensor 3, generates a control signal sent to the circuit of stepper motor 5 . The shaft of electric motor 5 converts its rotation in linear movement of rod 6 . Since rod 6 consists of two parts, one of which is rigidly connected to rail 2 of HPFP 1 and has an internal thread, the other is fixed in the support nut with the possibility of rotation, it has the ability to change its length due to the transmission 'screw-nut' 7 and reciprocatingly move rail 2, and therefore adjust the cyclic fuel supply according to the viscosity-temperature characteristics without disturbing the operation of the standard speed controller. For diesel operation in overload mode, it is possible to move rod 6 in conjugation, which is made based on the 'square squared' type with the possibility of axial movement. 


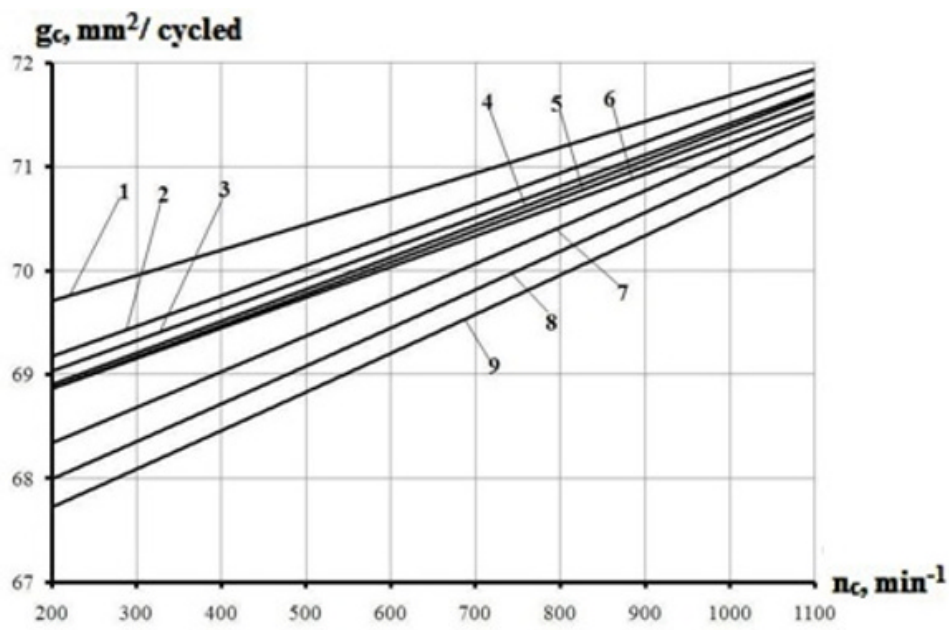

Fig. 6. The high-speed characteristic of HPFP with various concentrations of rapeseed oil in the MRMF when heating the fuel and using the proposed device: $1-100 \% \mathrm{DF}, 2-10 \% \mathrm{RO}, 3-25 \% \mathrm{RO}$, 4 -37\%RO, 5 - 50\%RO, $\quad 6$-63\%RO, 7 - 75\%RO, 8 - 90\%RO, 9 - 100\%RO

The results of the studies show that when taking the regulatory characteristic with the temperature of the mineral $\mathrm{DF}-30^{\circ} \mathrm{C}$ and heating MRMF to a temperature at which its viscosity is equal to the viscosity of the mineral DF $\left(t=30^{\circ} \mathrm{C}\right.$ ) (Figure 6), in the entire range of camshaft rotation frequencies of HPFP with the proposed device for adjusting the cyclic fuel supply, there is an equalization of the average volumetric cyclic feed of MRMF in comparison with studies without a corrector (Figure 3 and 4). For example, during tests on MRMF with the content of $90 \% \mathrm{VO}+10 \% \mathrm{DF}$ at the nominal revolution speed $\mathrm{n}=$ $1100 \mathrm{rpm}$, the average volumetric cyclic fuel supply increases to $\mathrm{g}_{ц}=71.3 \mathrm{~mm}^{3} /$ cycle, which corresponds to the permissible value.

\section{Conclusion}

From all of the above it follows that the content of rapeseed oil of $75 \%$ by volume and above in MRMF when it is heated to a temperature of $\left(\mathrm{t}=80^{\circ} \mathrm{C}\right)$ and the use of the proposed corrector for cyclic fuel supply is possible and appropriate.

\section{References}

1. Ukhanov A.P. The study of changes in the physical properties of mixed rapeseedmineral fuel at various temperatures [Text] / A.P. Ukhanov, A.S. Averyanov // Dostizheniya i prspektivy razvitiya biotekhnologii [Achievements and prospects for the development of biotechnology]: a collection of materials of the All-Russian NPK. Penza: RIO PGSHA, 2010. - pp. 9-13.

2. Averyanov A.S. Theoretical and experimental assessment of the effect of diesel mixed fuel on fuel supply parameters [Text] / A.S. Averyanov, A.P. Ukhanov, E.G. Rotanov // Izvestiya Samarskoy gosudarstvennoy selskokhozyaistvennoy akademii [Bulletin of the Samara State Agricultural Academy]. - 2011. - No. 3. - pp. 97-101.

3. Ukhanov A.P. Investigation of the influence of diesel mixed fuels of various compositions on the parameters of diesel fuel supply [Text] / A.P. Ukhanov, A.S. Averyanov // Vklad molodyh uchjonyh $v$ innovacionnoe razvitie APK Rossii [Contribution of young scientists to the innovative development of the agro-industrial 
complex of Russia]: a collection of materials of the All-Russian NPK. - Penza: RIO ПГСХА, 2010. - pp. 135-136.

4. Unconventional technologies. Energy of biowaste. Terms and definitions [Text]: GOST R 52808-2007. - Intro. 2007-12-27. - M.: Izd-vo Standartov Publ., 2007. - 25 p.

5. Fuel diesel pumps. General specifications [Text]: GOST 10578-95. - Instead of GOST 10578-86; Intro 1997-07-01. - M.: Izd-vo Standartov Publ., 2000. - 19 p.

6. Gorbanevsky V.E. Diesel fuel equipment: Optimization of the injection process, durability of parts and friction pairs / V.E. Gorbanevsky, V.G. Kislov, R.M. Bashirov et al. - M.: Izd-vo MGTU im. Baumana Publ., 1996. - 138 p.

7. Dobrodeev V.P. Calculation of thermodynamic processes in systems for supplying fuel to the engine / V.P. Dobrodeev, N.A. Mochalova // Izvestija vuzov. Aviacionnaja tehnika [University news. Aircraft technology]. - 1995. - No. 3. - pp. 49-52.

8. Ivashchenko N.A. Modeling of fuel supply processes and designing of fuel equipment for diesel engines / Ivashchenko N.A., Wagner V.A., Grekhov L.V. — Barnaul-M.: Altai State Technical University named after I.I. Polzunova Publ., 2002. — 166 p.

9. Grekhov L.V. Investigation of the possibility of obtaining increased injection pressures of divided type fuel supply equipment in automotive diesel engines / L.V. Grekhov, V.A. Markov, V.A. Pavlov et al. // Vestnik MGTU. Mashinostroenie. [Bulletin of MGTU. Mechanical engineering]. - 1997. - No. 1. - pp. 92-103. 